\title{
Article
}

\section{In Vitro Estimation of Relative Compliance during High-Frequency Oscillatory Ventilation}

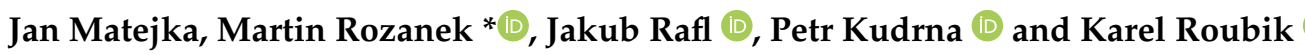 \\ Department of Biomedical Technology, Faculty of Biomedical Engineering, Czech Technical University in Prague, \\ nam. Sitna 3105, CZ-272 01 Kladno, Czech Republic; jan.matejka@fbmi.cvut.cz (J.M.); rafl@fbmi.cvut.cz (J.R.); \\ petr.kudrna@fbmi.cvut.cz (P.K.); roubik@fbmi.cvut.cz (K.R.) \\ * Correspondence: rozanek@fbmi.cvut.cz
}

Featured Application: Optimization of the mean pressure setting in high-frequency oscillatory ventilation.

check for updates

Citation: Matejka, J.; Rozanek, M.; Rafl, J.; Kudrna, P.; Roubik, K. In Vitro Estimation of Relative Compliance during High-Frequency Oscillatory Ventilation. Appl. Sci. 2021, 11, 899. https://doi.org/10.3390/app11030899

Received: 11 December 2020

Accepted: 15 January 2021

Published: 20 January 202

Publisher's Note: MDPI stays neutral with regard to jurisdictional claims in published maps and institutional affiliations.

Copyright: (c) 2021 by the authors. Licensee MDPI, Basel, Switzerland. This article is an open access article distributed under the terms and conditions of the Creative Commons Attribution (CC BY) license (https:// creativecommons.org/licenses/by/ $4.0 /)$.

\begin{abstract}
High-frequency oscillatory ventilation (HFOV), which uses a small tidal volume and a high respiratory rate, is considered a type of protective lung ventilation that can be beneficial for certain patients. A disadvantage of HFOV is its limited monitoring of lung mechanics, which complicates its settings and optimal adjustment. Recent studies have shown that respiratory system reactance $\left(X_{\mathrm{rs}}\right)$ could be a promising parameter in the evaluation of respiratory system mechanics in HFOV. The aim of this study was to verify in vitro that a change in respiratory system mechanics during HFOV can be monitored by evaluating $X_{\mathrm{rs}}$. We built an experimental system consisting of a 3100B high-frequency oscillatory ventilator, a physical model of the respiratory system with constant compliance, and a system for pressure and flow measurements. During the experiment, models of different constant compliance were connected to $\mathrm{HFOV}$, and $X_{\mathrm{rs}}$ was derived from the impedance of the physical model that was calculated from the spectral density of airway opening pressure and spectral cross-power density of gas flow and airway opening pressure. The calculated $X_{\mathrm{rs}}$ changed with the change of compliance of the physical model of the respiratory system. This method enabled monitoring of the trend in the respiratory system compliance during HFOV, and has the potential to optimize the mean pressure setting in HFOV in clinical practice.
\end{abstract}

Keywords: high-frequency oscillatory ventilation; continuous distending pressure; lung compliance; respiratory system reactance; rigid respiratory system model

\section{Introduction}

High-frequency oscillatory ventilation (HFOV) is a non-conventional mode of mechanical lung ventilation with a protective potential [1]. In clinical practice, HFOV is mainly used in patients suffering from acute respiratory distress syndrome (ARDS) who do not tolerate conventional mechanical ventilation (CMV) [2]. HFOV uses pressure oscillations to ensure effective elimination of carbon dioxide from the lungs of the ventilated subject. These pressure oscillations are superimposed on the continuous distension pressure (CDP), which keeps the lungs recruited, and together with the set fraction of inspired oxygen, ensures the oxygenation of the ventilated subject [3]. Despite its theoretical advantages, the practical suitability of HFOV is still debated [1,4-8], as there is a lack of recent studies that clearly demonstrate the clinical benefits of the technique for adult and pediatric patients. HFOV is therefore considered as a rescue intervention when adequate oxygenation cannot be achieved by CMV. The optimal management of HFOV, including CDP, which would be based on knowledge of lung mechanics of the patient, is unresolved, which could have contributed to inconsistent or negative conclusions of large multicenter HFOV studies $[9,10]$ and subsequent meta-analyses [11,12]. Recent studies have shown that an individual approach to HFOV settings could improve the patient's outcome $[13,14]$. Other 
monitoring methods should be involved to individualize HFOV settings, including electrical impedance tomography (EIT) [15], optoelectronic plethysmography [16], or respiratory system impedance analysis [17]. A lack of an individual approach to HFOV settings could have affected the outcome of earlier studies [18,19].

Currently, it is not clear how to set CDP properly with respect to an individual patient's airway condition. $C D P$ should be set to reach the maximal recruitment of the lungs while minimizing their overstrain [20]. An improperly high level of CDP can lead to ventilatorinduced lung injury. Many studies have been performed with an aim to obtain an optimal setting for CDP [21-28]. However, none of the suggested approaches have been broadly implemented in clinical practice, and CDP is commonly being set as a value of the mean airway pressure from the preceding $\mathrm{CMV}$ increased by several $\mathrm{cmH}_{2} \mathrm{O}$ [25]. Nevertheless, this way of setting $C D P$ is quite questionable [25]. As shown in [29], the CDP directly influences the compliance of the lungs, which is also tied to the recruitment (volume) of the lungs [29-31]. However, monitoring of the ventilation parameters is very limited in HFOV. For example, the 3100B ventilator (Vyaire Medical, Mettawa, IL, USA), which is commonly used in clinical practice for HFOV, and which was used in this study as well, does not enable monitoring of tidal volume or parameters of lung mechanics, such as lung compliance. This lack of monitoring ability also exists in the $3100 \mathrm{~A}$ ventilator (Vyaire Medical, Mettawa, IL, USA), which is suitable for the ventilation of neonatal and pediatric patients.

Recent studies have shown that reactance of the respiratory system $\left(X_{\mathrm{rs}}\right)$ measured using the forced oscillation technique (FOT) is a promising tool for evaluation of the mechanics of the respiratory system in HFOV [20,28]. During FOT, reactance is found using high-frequency pressure oscillations applied at the entrance of the respiratory system, and using the induced flow. Reactance is tied to compliance $(C)$, inertance $(L)$, and frequency of the pressure oscillations $(f)$ according to the equation:

$$
X_{\mathrm{rs}}=2 \cdot \pi \cdot f \cdot L-\frac{1}{2 \cdot \pi \cdot f \cdot C} .
$$

Inertance represents the tendency of a gas to remain in motion, and depends on the characteristics of the used ventilation gas mixture and geometric characteristics of the proximal airways [32]. The frequency of the pressure oscillations determines the sensitivity $X_{\mathrm{rs}}$ to the changes of the lung mechanics in different areas of the respiratory system [33]. The reactance $X_{\mathrm{rs}}$ measured at $f=5 \mathrm{~Hz}$ is a sensitive indicator of the changes of the mechanics in peripheral areas of the lungs [33-36]. Assuming a constant ventilation frequency and proximal airways with constant dimensions and stable shape, we consider the changes of inertance $L$ to be minimal. The first term of Equation (1) is therefore considered to be constant as well. On this assumption, the value of $X_{\mathrm{rs}}$ defined by the equation (1) is inversely proportional to the negative of the value of compliance $C$ of the ventilated system. A higher value of $C$ also means a higher value of $X_{\mathrm{rs}}$, i.e., $X_{\mathrm{rs}}$ is less negative, which is thus called relative compliance further in this study.

In a standard configuration of FOT, high-frequency oscillations are generated by a device connected to the inspiration branch of the patient circuit, and the flow is measured at the entrance to the respiratory system. Nonetheless, it has been shown that pressure oscillations generated by the ventilator during HFOV can be also used for the relative compliance measurement $[20,28]$. The method has been, however, successfully used in small animals (rabbits and preterm lambs), whose parameters of the respiratory system correspond to neonatal patients, but its use has not been verified in larger physical or animal models that would correspond to pediatric and adult patients.

The aim of this study is to verify whether it is possible, under laboratory conditions, to use pressure oscillations generated by the high-frequency oscillatory ventilator to determine relative compliance of the respiratory system from the measured proximal airway pressure and flow as a method that could be used for optimization of HFOV in pediatric and adult patients. 


\section{Materials and Methods}

The experiment setup is presented in Figure 1. In the experiment, we used a 3100B high-frequency oscillatory ventilator with a standard patient circuit for an adult patient. The patient circuit was connected to a glass container that represented the model of the respiratory system. The constant volume of the container determined its compliance. We gradually ventilated three different glass containers with volumes of 54,35 , and $25 \mathrm{~L}$, which represented respiratory systems with the values of compliance 37,24 , and $17 \mathrm{~mL} / \mathrm{cmH}_{2} \mathrm{O}$, respectively. The measurements were realized in two phases: with and without additional parabolic resistor Rp5 (Michigan Instruments, Grand Rapids, MI, USA), which simulated an increase in the flow resistance of the airways. In the laboratory experiment, we used the following ventilatory parameters: bias flow $=30 \mathrm{~L} / \mathrm{min}$, inspiration to expiration time ratio $I: E=1: 1$, ventilatory frequency $f=5 \mathrm{~Hz}, C D P=12 \mathrm{cmH}_{2} \mathrm{O}$, and amplitude of the pressure oscillations $\Delta P=20 \mathrm{cmH}_{2} \mathrm{O}$. The ventilatory parameters were determined according to [37]. In clinical practice, the $C D P$ and $\triangle P$ are titrated at the start of HFOV to reach physiological levels of $\mathrm{P}_{\mathrm{a}} \mathrm{O}_{2}$ and $\mathrm{P}_{\mathrm{a}} \mathrm{CO}_{2}$. We did not titrate $C D P$ and $\Delta P$ in the ventilation because there was no gas exchange in our in vitro laboratory experiment. Pressure $p_{\text {aw }}$ and flow $q_{\mathrm{aw}}$ of the air were recorded at the entry of the model of the respiratory system using a measuring system designed for HFOV monitoring [38]. The flow was measured as a pressure difference across the orifice. Both $p_{\mathrm{aw}}$ and $q_{\mathrm{aw}}$ signals were recorded using a sampling frequency of $1000 \mathrm{~Hz}$.

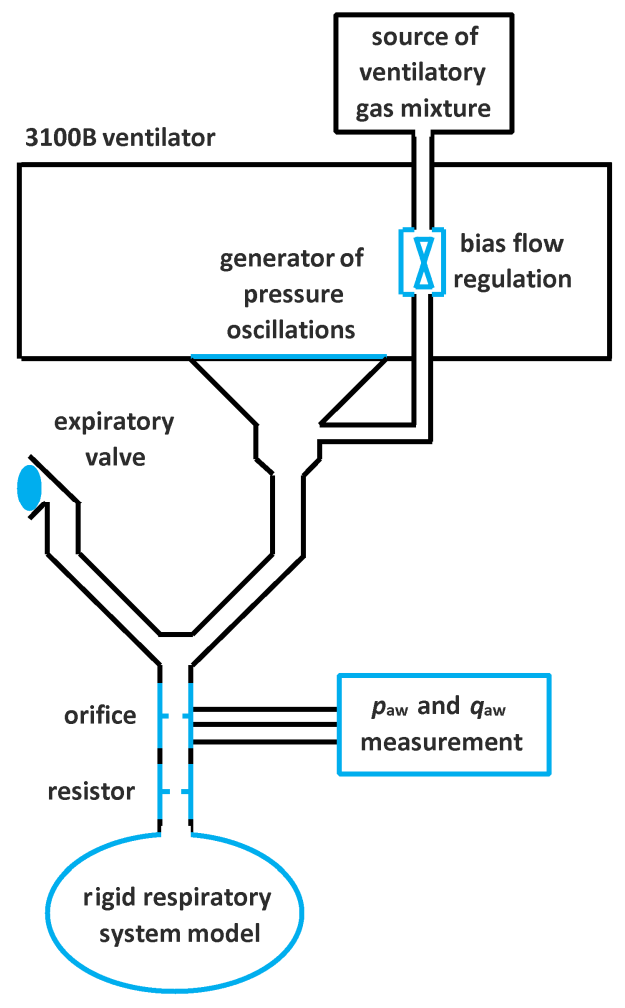

Figure 1. The arrangement of the experiment.

The relative compliance $X_{\mathrm{rs}}$ was calculated based on the power-spectral density $S_{\mathrm{xx}}$ of the pressure and the cross-spectral density $S_{\mathrm{yx}}$ of flow and pressure. The spectral densities were calculated from $p_{\mathrm{aw}}$ and $q_{\mathrm{aw}}$ using windows with a width of $2 \mathrm{~s}$ that moved along the signals with a step of $1 \mathrm{~s}$. In the windows, the average value of a signal in the time domain was subtracted from the signal to remove the DC component in the frequency domain. Both spectral densities $S_{\mathrm{xx}}$ and $S_{\mathrm{yx}}$ were calculated using Welch's averaged modified periodogram method of spectral estimation [39]. When calculating the spectral densities, sections of both signals within the same window were split into eight segments, with a 50\% 
overlap between the neighboring segments. In a particular 2-s window, an $i$-th sample $y_{K}(i)$ of the $K$-th segment of the $p_{\mathrm{aw}}$ or $q_{\mathrm{aw}}$ signal was thus acquired as:

$$
y_{K}=y(i+(K-1) \cdot 222),
$$

where $y$ represents the $p_{\mathrm{aw}}$ or $q_{\mathrm{aw}}$ signal in the window, $i$ has a range of 1 to 444 , and $K$ has a range of 1 to 8 . Each segment $y_{K}$ was filtered in the time domain by a low-pass FIR filter using the Hamming window. Fourier transforms $P_{K}$ and $Q_{K}$ of $y_{K}$ were obtained for the pressure and flow signal segments, respectively. Modified periodograms $I_{K}$ of $K$-th segment were calculated from $P_{K}$ and $Q_{K}$ as:

$$
I_{K}=\frac{1}{w^{T} \cdot w} \cdot P_{K} \cdot P_{K}^{*}
$$

for $S_{\mathrm{xx}}$ and as:

$$
I_{K}=\frac{1}{w^{T} \cdot w} \cdot Q_{K} \cdot P_{K}^{*}
$$

for $S_{\mathrm{yx}}$. In equations (3) and (4), $P_{K^{*}}$ represents a complex conjugate of $P_{K}, w$ is a column vector of coefficients of the previously used Hamming window, and $w^{T}$ represents the transpose of $w$. Finally, the spectral densities $S_{\mathrm{xx}}$ and $S_{\mathrm{yx}}$ were calculated as an average value of $I_{K}$ in a given window. In the $S_{\mathrm{xx}}$ and $S_{\mathrm{yx}}$, the frequency $f_{\max }$ corresponding to the maximal power was found. This frequency corresponds with the fundamental waveform (first harmonic frequency) of the oscillations generated by the ventilator, which was set in the study as a nominal frequency $f=5 \mathrm{~Hz}$.

The next step in the calculation of $X_{\mathrm{rs}}$ was calculating the amplitude $Z_{\mathrm{mag}}$ and the angle $Z_{\text {ang }}$ of the impedance of the respiratory system based on equations [40]:

$$
\begin{gathered}
Z_{\mathrm{mag}}=\frac{S_{\mathrm{xx}}\left(f_{\max }\right)}{\left|S_{\mathrm{yx}}\left(f_{\max }\right)\right|}, \\
Z_{\text {ang }}=-\tan ^{-1}\left[\frac{\operatorname{Im}\left(S_{\mathrm{yx}}\right)}{\operatorname{Re}\left(S_{\mathrm{yx}}\right)}\right] .
\end{gathered}
$$

The relative compliance $X_{\mathrm{rs}}$ was then calculated by converting the respiratory system impedance from polar coordinates to Cartesian according to Equation (7):

$$
X_{\mathrm{rs}}=Z_{\mathrm{mag}} \cdot \sin \left(Z_{\mathrm{ang}}\right) .
$$

\section{Results}

The course of $X_{\mathrm{rs}}$ is shown in Figure 2 during the measurement of the modeled respiratory system without $\left(R=0 \mathrm{cmH}_{2} \mathrm{O} \cdot \mathrm{s} / \mathrm{L}\right)$ and with an added resistor $\left(R=5 \mathrm{cmH}_{2} \mathrm{O} \cdot \mathrm{s} / \mathrm{L}\right)$, with three sizes of the glass container $(54 \mathrm{~L}, 35 \mathrm{~L}$, and $25 \mathrm{~L})$. The relative compliance $X_{\mathrm{rs}}$ determined from the pressure $p_{\mathrm{aw}}$ and flow $q_{\mathrm{aw}}$ in the respiratory circuit decreased with the value of the volume of the used rigid container, and therefore with decreasing compliance. When measuring with an additional resistor, we detected higher values of $X_{\mathrm{rs}}$ compared to the corresponding measurements without the resistor. 


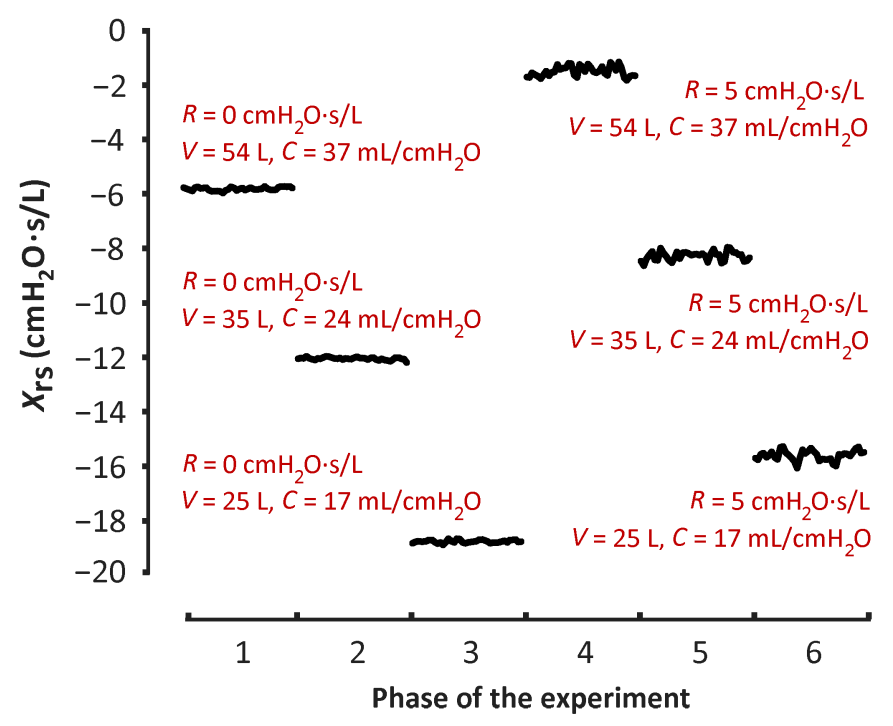

Figure 2. The waveform of $X_{\mathrm{rs}}$ when ventilating a model of the respiratory system without an additional resistor $\left(R=0 \mathrm{cmH}_{2} \mathrm{O} \cdot \mathrm{s} / \mathrm{L}\right)$ and with an additional resistor $\left(R=5 \mathrm{cmH}_{2} \mathrm{O} \cdot \mathrm{s} / \mathrm{L}\right)$. Three glass containers with different volumes $(25,35$, and $54 \mathrm{~L})$ were ventilated with and without the resistor to mimic various compliance of the respiratory system.

The average values of $X_{\mathrm{rs}}$ for each volume $V$ of used rigid containers are summarized in Table 1 for measurements both with and without an additional resistor.

Table 1. Summary of the detected values of $X_{\mathrm{rs}}\left(\mathrm{cmH}_{2} \mathrm{O} \cdot \mathrm{s} / \mathrm{L}\right)$.

\begin{tabular}{ccccc}
\hline $\boldsymbol{V}(\mathrm{L})$ & \multicolumn{2}{c}{$\mathbf{X}_{\text {rs }}$ with No Resistor } & \multicolumn{2}{c}{$\mathbf{X}_{\text {rs }}$ with Added Resistor } \\
\hline & Mean & SD $^{\mathbf{1}}$ & Mean & SD $^{\mathbf{1}}$ \\
\hline 54 & -5.82 & 0.06 & -1.56 & 0.17 \\
35 & -12.07 & 0.05 & -8.26 & 0.17 \\
25 & -18.76 & 0.06 & -15.62 & 0.17 \\
\hline
\end{tabular}

${ }^{1} \mathrm{SD}$ is an abbreviation for standard deviation.

\section{Discussion}

The results of this study showed that during HFOV, it is possible to monitor changes in trend in respiratory system compliance by analysis of reactance. According to the models, even the very peripheral lung segment compliances propagated to the proximal value of the total respiratory system compliance [41]. We conducted an in vitro laboratory experiment using defined physical models of the respiratory system with various values of compliance and flow resistance. Using the processing of the pressure and flow signals, we calculated reactance of the ventilated physical model, and showed that changes in the reactance corresponded to changes in compliance of the model.

The results show that it is possible to monitor compliance changes during HFOV on various levels of flow resistance. The Rp5 resistor simulated an increase in the airway resistance, and its addition to the physical model resulted in an increase in the value of the measured $X_{\mathrm{rs}}$ when compared to ventilation of the same rigid container in the model without the added Rp5 resistor. The inertance of a tube of a circular cross-section is inversely proportional to its cross-section. When we added the Rp5 resistor into the model of the respiratory system, we created a narrowing, which not only increased the flow resistance, but also led to an increase of inertance $L$, therefore increasing $X_{\mathrm{rs}}$, as shown by Equation (1). Nevertheless, in clinical practice, no major change in airway resistance in ventilated patients is likely to occur during short periods of titrating $C D P$. Under this assumption, the effect of resistance on the assessment of changes in respiratory system compliance from $X_{\text {rs }}$ can be neglected. 
An in vitro experiment with a rigid-wall glass container allowed us to evaluate the method of $X_{\mathrm{rs}}$ analysis for the trend estimation of the respiratory system compliance under stable conditions. In previous studies, the analysis of the spectral density of pressure and flow in the ventilatory circuit was conducted within the experiment on small laboratory animals: rabbits and preterm lambs. Before applying the same method of $X_{\mathrm{rs}}$ analysis on data from large subjects, we wished to evaluate the method on the data acquired under the condition of well-defined and stable lung compliance corresponding to the lung compliance of pediatric and adult patients. Our results were in concordance with [20,28], and suggested that the method of $X_{\mathrm{rs}}$ analysis is also suitable for analysis of pulmonary mechanics of ventilated large laboratory animals.

The values of the standard deviation of $X_{\mathrm{rs}}$ were very low (Table 1$)$, which indicates a good robustness of the algorithm for $X_{\mathrm{rs}}$ calculation. The oscillation of $X_{\mathrm{rs}}$ around the average value was caused by the noise in the measured pressure and flow signals. Table 1 shows that the addition of the resistor into the ventilated system led to an increase in the value of the standard deviation of $X_{\mathrm{rs}}$. This was caused by an increased noise amplitude in the flow signal after the addition of the resistor, as shown in Figure 3, in which the flow signals without and with the added resistor during one breathing cycle are compared.

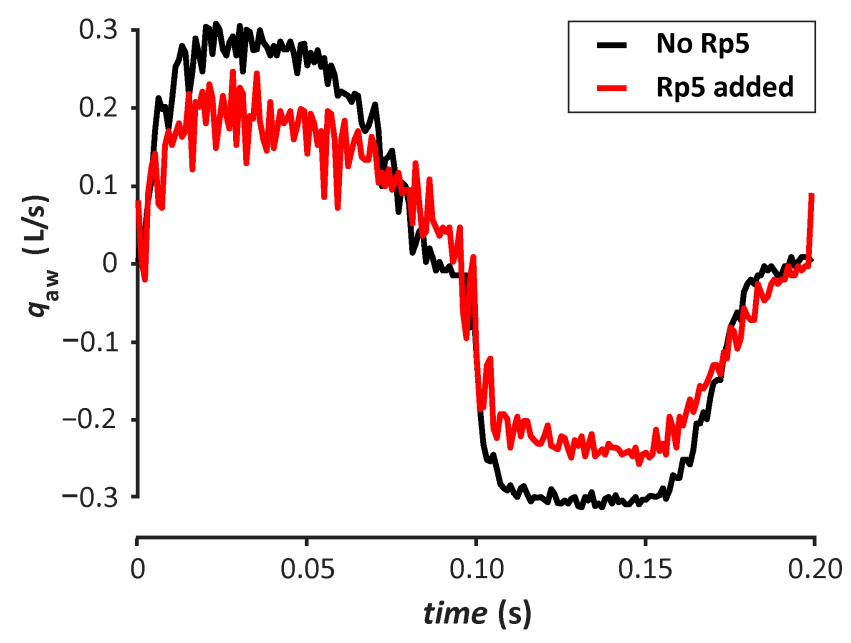

Figure 3. Comparison of the measured flow signal prior to and after the addition of the Rp5 resistor.

The presented method for measurement of $X_{\mathrm{rs}}$ during HFOV is simple enough to be used bedside. The single component added into the patient circuit is an orifice for pressure and flow measurement. In our study, we used a system that consists of the orifice, sensors, digitizing hardware, and a laptop with evaluation software [38]; in a clinical scenario, any standard monitoring device capable of proximal pressure and flow measurement and real-time data streaming would be feasible. A possible disadvantage of this method is an increase of the flow resistance, together with the dead space when the orifice (used for pressure and flow measurement) is added into the patient circuit. A limitation of our study is that the test used a single ventilator model with a frequency $f=5 \mathrm{~Hz}$. This choice was based on previous studies [33-36], and we did not investigate the possible use of other ventilatory frequencies.

As the described method allows determination of relative compliance with respect to airway inertance and resistance, its practical application is predetermined to maneuvers, during which the change in lung compliance is the dominant parameter affecting changes in respiratory system mechanics. An example of such a maneuver, and thus a possible advantage of using the relative compliance determination, is optimizing $C D P$ in the initial phase of HFOV or its reassessment during the course of ventilation. Another advantage of relative compliance determination could be evaluating efficiency of recruitment maneuver, commonly implemented as a stepwise increase and consequent decrease of $C D P$, while evaluating influenced physiological parameters [42]. In these situations, when a 
constant airway inertance and resistance can be assumed, observing a short-time trend of relative compliance gives a faster response than standard methods that utilize assessment of the respiratory gas exchange. Because maximal compliance and maximal carbon dioxide elimination are highly correlated [29], relative compliance change could indicate appropriateness of a conducted CDP-optimization step. Suter et al. [43] documented that in adult patients with atelectatic lung disease, both underinflation and overinflation of the lungs impaired lung compliance. Changes in functional residual capacity during a recruitment procedure impact lung compliance as the position of ventilation changes along the inflation and deflation limbs of the pressure-volume curve [44]. As a consequence, a decrease in the relative lung compliance indicates moving ventilation outside of the linear lung-compliance region (i.e., it is able to detect either emerging lung collapse or lung hyperinflation). This method of relative lung compliance measurement could also facilitate control of modern ventilators that use mathematical modeling of the respiratory system as an integral part of their control systems, real-time systems for support of spontaneous breathing during HFOV, and in other applications with advanced control systems [45-47].

\section{Conclusions}

In this in vitro study, we verified the possibility of monitoring the relative compliance of lungs during HFOV in laboratory conditions using the model of large laboratory animal. The results of the study showed that the monitoring of relative compliance in laboratory conditions is possible. The method we used is simple enough for bedside use in clinical practice, and seems to be suitable for real-time monitoring as well. The method could allow the evaluation of changes in respiratory system compliance related to the setting of CDP during HFOV of large laboratory animals and pediatric and adult patients. It could help physicians or respiratory therapists to assess the trend in compliance of the respiratory system when its direct measurement is not available, and the information could be used for optimizing CDP in HFOV.

Author Contributions: Conceptualization, M.R.; methodology, J.M.; software, J.M.; validation, J.R.; formal analysis, J.M.; investigation, M.R.; resources, P.K.; data curation, J.M.; writing—original draft preparation, J.M.; writing-review and editing, M.R., J.R., K.R.; visualization, J.M., K.R.; supervision, M.R., K.R.; project administration, M.R.; funding acquisition, M.R. All authors have read and agreed to the published version of the manuscript.

Funding: This work was supported by projects SGS19/202/OHK4/3T/17 and SGS20/202/OHK4/ $3 \mathrm{~T} / 17$.

Institutional Review Board Statement: Not applicable.

Informed Consent Statement: Not applicable.

Data Availability Statement: The data presented in this study are available on request from the corresponding author.

Conflicts of Interest: The authors declare no conflict of interest.

\section{References}

1. Meade, M.O.; Young, D.; Hanna, S.; Zhou, Q.; Bachman, T.E.; Bollen, C.; Slutsky, A.S.; Lamb, S.E.; Adhikari, N.K.; Mentzelopoulos, S.D.; et al. Severity of Hypoxemia and Effect of High-Frequency Oscillatory Ventilation in Acute Respiratory Distress Syndrome. Am. J. Respir. Crit. Care Med. 2017, 196, 727-733. [CrossRef]

2. Sud, S.; Sud, M.; Friedrich, J.O.; Meade, M.O.; Ferguson, N.D.; Wunsch, H.; Adhikari, N.K. High frequency oscillation in patients with acute lung injury and acute respiratory distress syndrome (ARDS): Systematic review and meta-analysis. BMJ 2010, 340, c2327. [CrossRef]

3. Sklar, M.C.; Fan, E.; Goligher, E.C. High-Frequency Oscillatory Ventilation in Adults With ARDS: Past, Present, and Future. Chest 2017, 152, 1306-1317. [CrossRef]

4. Ng, J.; Ferguson, N.D. High-frequency oscillatory ventilation: Still a role? Curr. Opin. Crit. Care 2017, 23, 175-179. [CrossRef] [PubMed]

5. Goligher, E.C.; Munshi, L.; Adhikari, N.K.; Meade, M.O.; Hodgson, C.L.; Wunsch, H.; Uleryk, E.; Gajic, O.; Amato, M.P.; Ferguson, N.D.; et al. High-Frequency Oscillation for Adult Patients with Acute Respiratory Distress Syndrome. A Systematic Review and Meta-Analysis. Ann. Am. Thorac. Soc. 2017, 14, S289-S296. [CrossRef] 
6. Wong, J.J.; Liu, S.; Dang, H.; Anantasit, N.; Phan, P.H.; Phumeetham, S.; Qian, S.; Ong, J.S.; Gan, C.S.; Chor, Y.K.; et al. The impact of high frequency oscillatory ventilation on mortality in paediatric acute respiratory distress syndrome. Crit. Care 2020, 24,31 . [CrossRef] [PubMed]

7. Angriman, F.; Ferreyro, B.L.; Donaldson, L.; Cuthbertson, B.H.; Ferguson, N.D.; Bollen, C.W.; Bachman, T.E.; Lamontagne, F.; Adhikari, N.K. The harm of high-frequency oscillatory ventilation (HFOV) in ARDS is not related to a high baseline risk of acute cor pulmonale or short-term changes in hemodynamics. Intensive Care Med. 2020, 46, 132-134. [CrossRef] [PubMed]

8. Ning, B.; Liang, L.; Lyu, Y.; Yu, Y.; Li, B. The effect of high-frequency oscillatory ventilation or airway pressure release ventilation on children with acute respiratory distress syndrome as a rescue therapy. Transl. Pediatr. 2020, 9, 213-220. [CrossRef]

9. Ferguson, N.D.; Cook, D.J.; Guyatt, G.H.; Mehta, S.; Hand, L.; Austin, P.; Zhou, Q.; Matte, A.; Walter, S.D.; Lamontagne, F.; et al. High-frequency oscillation in early acute respiratory distress syndrome. N. Engl. J. Med. 2013, 368, 795-805. [CrossRef]

10. Young, D.; Lamb, S.E.; Shah, S.; MacKenzie, I.; Tunnicliffe, W.; Lall, R.; Rowan, K.; Cuthbertson, B.H. High-frequency oscillation for acute respiratory distress syndrome. N. Engl. J. Med. 2013, 368, 806-813. [CrossRef]

11. Gu, X.L.; Wu, G.N.; Yao, Y.W.; Shi, D.H.; Song, Y. Is high-frequency oscillatory ventilation more effective and safer than conventional protective ventilation in adult acute respiratory distress syndrome patients? A meta-analysis of randomized controlled trials. Crit. Care 2014, 18, R111. [CrossRef]

12. Maitra, S.; Bhattacharjee, S.; Khanna, P.; Baidya, D.K. High-frequency ventilation does not provide mortality benefit in comparison with conventional lung-protective ventilation in acute respiratory distress syndrome: A meta-analysis of the randomized controlled trials. Anesthesiology 2014, 122, 841-851. [CrossRef] [PubMed]

13. de Jager, P.; Kamp, T.; Dijkstra, S.K.; Burgerhof, J.G.; Markhorst, D.G.; Curley, M.A.; Cheifetz, I.M.; Kneyber, M.C. Feasibility of an alternative, physiologic, individualized open-lung approach to high-frequency oscillatory ventilation in children. Ann. Intensive Care 2019, 9, 9. [CrossRef] [PubMed]

14. de Jager, P.; Burgerhof, J.G.; Koopman, A.A.; Markhorst, D.G.; Kneyber, M.C. Physiologic responses to a staircase lung volume optimization maneuver in pediatric high-frequency oscillatory ventilation. Ann. Intensive Care 2020, 10, 153. [CrossRef]

15. Liu, S.; Zhao, Z.; Tan, L.; Wang, L.; Möller, K.; Frerichs, I.; Yu, T.; Huang, Y.; Pan, C.; Yang, Y.; et al. Optimal mean airway pressure during high-frequency oscillatory ventilation in an experimental model of acute respiratory distress syndrome: EIT-based method. Ann. Intensive Care 2020, 10, 31. [CrossRef] [PubMed]

16. Lista, G.; Bresesti, I.; Cavigioli, F.; Castoldi, F.; Lupo, E.; LoMauro, A.; Aliverti, A. Efficacy of lung volume optimization maneuver monitored by optoelectronic pletismography in the management of congenital diaphragmatic hernia. Respir. Med. Case Rep. 2017, 22, 133-136. [CrossRef]

17. Zannin, E.; Dellaca, R.L.; Dognini, G.; Marconi, L.; Perego, M.; Pillow, J.J.; Tagliabue, P.E.; Ventura, M.L. Effect of frequency on pressure cost of ventilation and gas exchange in newborns receiving high-frequency oscillatory ventilation. Pediatr. Res. 2017, 82, 994-999. [CrossRef]

18. Kneyber, M.C.; Markhorst, D.G. Do We Really Know How to Use High-Frequency Oscillatory Ventilation in Critically Ill Children? Am. J. Respir. Crit. Care Med. 2016, 193, 1067-1068. [CrossRef]

19. Kneyber, M.C.; Markhorst, D.G. Any trial can (almost) kill a good technique. Intensive Care Med. 2016, 42, 1092-1093. [CrossRef]

20. Dellacà, R.L.; Zannin, E.; Ventura, M.L.; Sancini, G.; Pedotti, A.; Tagliabue, P.; Miserocchi, G. Assessment of dynamic mechanical properties of the respiratory system during high-frequency oscillatory ventilation. Crit. Care Med. 2013, 41, 2502-2511. [CrossRef]

21. Casserly, B.; McCool, F.D.; Sethi, J.M.; Kawar, E.; Read, R.; Levy, M.M. A method for determining optimal mean airway pressure in high-frequency oscillatory ventilation. Lung 2013, 191, 69-76. [CrossRef] [PubMed]

22. van Genderingen, H.R.; van Vught, J.A.; Jansen, J.R.; Duval, E.L.; Markhorst, D.G.; Versprille, A. Oxygenation index, an indicator of optimal distending pressure during high-frequency oscillatory ventilation? Intensive Care Med. 2002, 28, 1151-1156. [CrossRef]

23. Goddon, S.; Fujino, Y.; Hromi, J.M.; Kacmarek, R.M. Optimal mean airway pressure during high-frequency oscillation: Predicted by the pressure-volume curve. Anesthesiology 2001, 94, 862-869. [CrossRef] [PubMed]

24. Habib, R.H.; Pyon, K.H.; Courtney, S.E. Optimal high-frequency oscillatory ventilation settings by nonlinear lung mechanics analysis. Am. J. Respir. Crit. Care Med. 2002, 166, 950-953. [CrossRef] [PubMed]

25. Klapsing, P.; Moerer, O.; Wende, C.; Herrmann, P.; Quintel, M.; Bleckmann, A.; Heuer, J.F. High-frequency oscillatory ventilation guided by transpulmonary pressure in acute respiratory syndrome: An experimental study in pigs. Crit. Care 2018, 22, 121. [CrossRef] [PubMed]

26. Klapsing, P.; Moerer, O.; Wende, C.; Herrmann, P.; Quintel, M.; Bleckmann, A.; Heuer, J.F. Setting mean airway pressure during high-frequency oscillatory ventilation according to the static pressure-volume curve in surfactant-deficient lung injury: A computed tomography study. Anesthesiology 2003, 99, 1313-1322. [CrossRef]

27. Tingay, D.G.; Mills, J.F.; Morley, C.J.; Pellicano, A.; Dargaville, P.A. Indicators of optimal lung volume during high-frequency oscillatory ventilation in infants. Crit. Care Med. 2013, 41, 237-244. [CrossRef]

28. Zannin, E.; Ventura, M.L.; Dellacà, R.L.; Natile, M.; Tagliabue, P.; Perkins, E.J.; Sourial, M.; Bhatia, R.; Dargaville, P.A.; Tingay, D.G. Optimal mean airway pressure during high-frequency oscillatory ventilation determined by measurement of respiratory system reactance. Pediatr. Res. 2014, 75, 493-499. [CrossRef]

29. Miedema, M.; de Jongh, F.H.; Frerichs, I.; van Veenendaal, M.B.; van Kaam, A.H. The effect of airway pressure and oscillation amplitude on ventilation in pre-term infants. Eur. Respir. J. 2012, 40, 479-484. [CrossRef] 
30. Pillow, J.J. Tidal volume, recruitment and compliance in HFOV: Same principles, different frequency. Eur. Respir. J. 2012, 40, 291-293. [CrossRef]

31. Kung, S.C.; Hung, Y.L.; Chen, W.L.; Wang, C.M.; Chang, H.C.; Liu, W.L. Effects of Stepwise Lung Recruitment Maneuvers in Patients with Early Acute Respiratory Distress Syndrome: A Prospective, Randomized, Controlled Trial. J. Clin. Med. 2019,8 , 231. [CrossRef] [PubMed]

32. Bates, J.H. The Role of Airway Shunt Elastance on the Compartmentalization of Respiratory System Impedance. J. Eng. Sci. Med. Diagn. Ther. 2019, 2, 110011-110018. [CrossRef] [PubMed]

33. Brashier, B.; Salvi, S. Measuring lung function using sound waves: Role of the forced oscillation technique and impulse oscillometry system. Breathe 2015, 11, 57-65. [CrossRef] [PubMed]

34. Shimoda, T.; Obase, Y.; Nagasaka, Y.; Kishikawa, R.; Mukae, H.; Iwanaga, T. Peripheral bronchial obstruction evaluation in patients with asthma by lung sound analysis and impulse oscillometry. Allergol. Int. 2017, 66, 132-138. [CrossRef] [PubMed]

35. Aronsson, D.; Hesselstrand, R.; Bozovic, G.; Wuttge, D.M.; Tufvesson, E. Airway resistance and reactance are affected in systemic sclerosis. Eur. Clin. Respir. J. 2015, 2, 28667. [CrossRef]

36. Bhattarai, P.; Myers, S.; Chia, C.; Weber, H.C.; Young, S.; Williams, A.D.; Sohal, S.S. Clinical Application of Forced Oscillation Technique (FOT) in Early Detection of Airway Changes in Smokers. J. Clin. Med. 2020, 9, 2778. [CrossRef]

37. Fessler, H.E.; Derdak, S.; Ferguson, N.D.; Hager, D.N.; Kacmarek, R.M.; Thompson, B.T.; Brower, R.G. A protocol for highfrequency oscillatory ventilation in adults: Results from a roundtable discussion. Crit. Care Med. 2007, 35, 1649-1654. [CrossRef]

38. Roubik, K. Measuring and evaluating system designed for high-frequency oscillatory ventilation monitoring. Biomed. Tech. 2014. [CrossRef]

39. Welch, P. The use of fast Fourier transform for the estimation of power spectra: A method based on time averaging over short, modified periodograms. IEEE Trans. Audio Electroacoust. 1967, 15, 70-73. [CrossRef]

40. Michaelson, E.D.; Grassman, E.D.; Wendell, R.P. Pulmonary mechanics by spectral analysis of forced random noise. J. Clin. Invest. 1975, 56, 1210-1230. [CrossRef]

41. Rožánek, M.; Horáková, Z.; Čadek, O.; Kučera, M.; Roubík, K. Damping of the dynamic pressure amplitude in the ventilatory circuit during high-frequency oscillatory ventilation. Biomed. Eng. Biomed. Tech. 2012, 57, 53-56. [CrossRef] [PubMed]

42. Laviola, M.; Rafl, J.; Rozanek, M.; Kudrna, P.; Roubik, K. Models of PaO2 response to the continuous distending pressure maneuver during high frequency oscillatory ventilation in healthy and ARDS lung model pigs. Exp. Lung Res. 2016, 42, 87-94. [CrossRef] [PubMed]

43. Suter, P.M.; Fairley, H.B.; Isenberg, M.D. Optimum endexpiratory airway pressure in patients with acute pulmonary failure. N. Engl. J. Med. 1975, 292, 284-289. [CrossRef] [PubMed]

44. Dargaville, P.A.; Rimensberger, P.C.; Frerichs, I. Regional tidal ventilation and compliance during a stepwise vital capacity manoeuvre. Intensive Care Med. 2010, 36, 1953-1961. [CrossRef]

45. Dellaca, R.L.; Veneroni, C. Trends in mechanical ventilation: Are we ventilating our patients in the best possible way? Breathe 2017, 13, 84-98. [CrossRef]

46. Roubík, K.; Ráfl, J.; van Heerde, M.; Markhorst, D.G. Design and control of a demand flow system assuring spontaneous breathing of a patient connected to an HFO ventilator. IEEE Trans. Biomed. Eng. 2011, 58, 3225-3233. [CrossRef]

47. Van Heerde, M.; Roubik, K.; Kopelent, V.; Plötz, F.B.; Markhorst, D.G. Demand flow facilitates spontaneous breathing during high-frequency oscillatory ventilation in a pig model. Crit. Care Med. 2009, 37, 1068-1073. [CrossRef] 